TAO, Vol. 15, No. 2, 179-197, June 2004

\title{
Statistical Comparisons of Some External Morphometrical Aspects of the Swimming Crab Protunus sanguinolentus (Herbst) Populations Inhabiting the Keelung Shelf and Taiwan Bank.
}

\author{
Hsiao-Chuan Chang ${ }^{1}$ and Chien-Chung $\mathrm{Hsu}^{1, *}$ \\ (Manuscript received 29 September 2003, in final form 30 March 2004)
}

\begin{abstract}
Five external morphometric characters and size at maturity in carapace width of the swimming crab, Protunus sanguinolentus, were examined and compared between sampling groups obtained from the Keelung Shelf and Taiwan Bank. The external morphometric characters used in the present study are: carapace width, carapace length, distance between two sides of first spine, fifth abdominal segment width, fifth abdominal segment length, chela length, chela width and movable dactylus length. Two statistical approaches were applied, i.e. multivariate morphometric analysis was used to compare external morphometric characters and a likelihood ratio test was used to compare maturity curves. Both results obtained show significant differences between the two sampling groups. The size at maturity was represented by $\mathrm{LM}_{50}$ and estimated theoretically from maturity curves, indicating that $\mathrm{LM}_{50}$ for females is $\mathbf{9 7 . 0 0} \mathbf{~ m m ~ C W}$ in Keelung Shelf, and 82.36 $\mathrm{mm} \mathrm{CW}$ in Taiwan Bank, whilst for males it is $92.62 \mathrm{~mm} \mathrm{CW}$ in both areas. The results of statistical comparisons are coincident that external morphometric characters of female Protunus sanguinolentus between the waters off the Keelung Shelf and the Taiwan Bank are significantly different.
\end{abstract}

(Key words: Morphometric characters, Size at maturity, Canonical discriminant analysis, Likelihood ratio test)

\section{INTRODUCTION}

The swimming crab Portunus sanguinolentus (Herbst 1783) is mainly distributed in IndoPacific tropic regions from East African to Hawaiian waters (Stephenson and Campbell 1959; Sumpton et al. 1989). It inhabits sand or mud-sand substrates at different depth depending on

\footnotetext{
${ }^{1}$ Institute of Oceanography, National Taiwan University, Taipei, Taiwan, ROC

* Corresponding author address: Prof. Chien-Chung Hsulnstitute of Oceanography, National Taiwan University, Taipei, Taiwan, ROC, E-mail: hsucc@ccms.ntu.edu.tw
} 
its life stage. Juveniles are often found more highly concentrated in estuaries and in shore waters, while adults are more abundant in deep waters (Wenner 1972; Campbell and Fielder 1986).

The swimming crab has a strong capability of spreading during both larval and adult phases. Larvae could recruit into other spatially isolated populations through long distance transportation controlled by oceanic circulation (Johnson et al. 1984; Johnson et al. 1986; Hobbs et al. 1992; Mense et al. 1995). Information on oceanographic conditions can help to understand larva dispersion within its habitat. Furthermore, most sorts of oceanic conditions such as oceanographic discontinuities, bio-geographic boundaries, varying climatic regimes and diversities of habitat, etc. can limit distribution of their movements.

Around Taiwan waters, only two traditional fishing grounds, the Keelung Shelf in the north and the Taiwan Bank to the southwest, have known populations of the swimming crab (Hsu et al. 2002). This occurrence may introduce substantially important information on the Portunus sanguinolentus stock structures around Taiwan waters.

Various approaches have been applied to study the stock delineation of swimming crabs. Typically, multivariate statistical comparisons of morphometric characteristics have been statistically acceptable and powerful (e.g., Melvin et al. 1992; Chu et al. 1995; Harriet et al. 1995; Overton et. al. 1997; Bowering et al. 1998). Therefore, the purpose of this present paper is to use statistical analyses to compare external morphometric characters and size at maturity of swimming crabs in order to verify the discrepancies of some external morphometric features of Portunus sanguinolentus populations that are spatially isolated in this particular geographical area.

\section{MATERIALS AND METHODS}

\subsection{Sample collection and measurement}

Swimming crab samples used in this study were randomly collected from catches of two traditional fishing grounds (Fig.1) during January to April in 1998. Detailed sampling information is summarized in Table 1. Only specimens with all morphometric characters available were measured and used in the statistical analysis because "missing observations virtually destroy morphometrics" (Pimentel 1979). For this reason, the dataset of February 1998 was discarded.

Furthermore, in order to take account of sexual dimorphism with respect to morphometric characters (Hsu et al. 2000) and the allometric growth (differential increase rate) of morphometric characters in the life strata (Safran 1992; Lee and Hsu 2003) between sexes, measurements were taken separately by sex. Also since the biological properties mentioned above might result in greater variations attributable to morphometrical characters than geographic location between stocks, only mature female individuals were used in this study to diminish variance.

Consequently, a total 258 individuals was selected for morphometric measurements (Table 1) and eight morphometrical characters (CW, carapace width; CL, carapace length; CWIS, distance between two sides of the first spine; FAB, fifth abdominal segment width; FABL, 


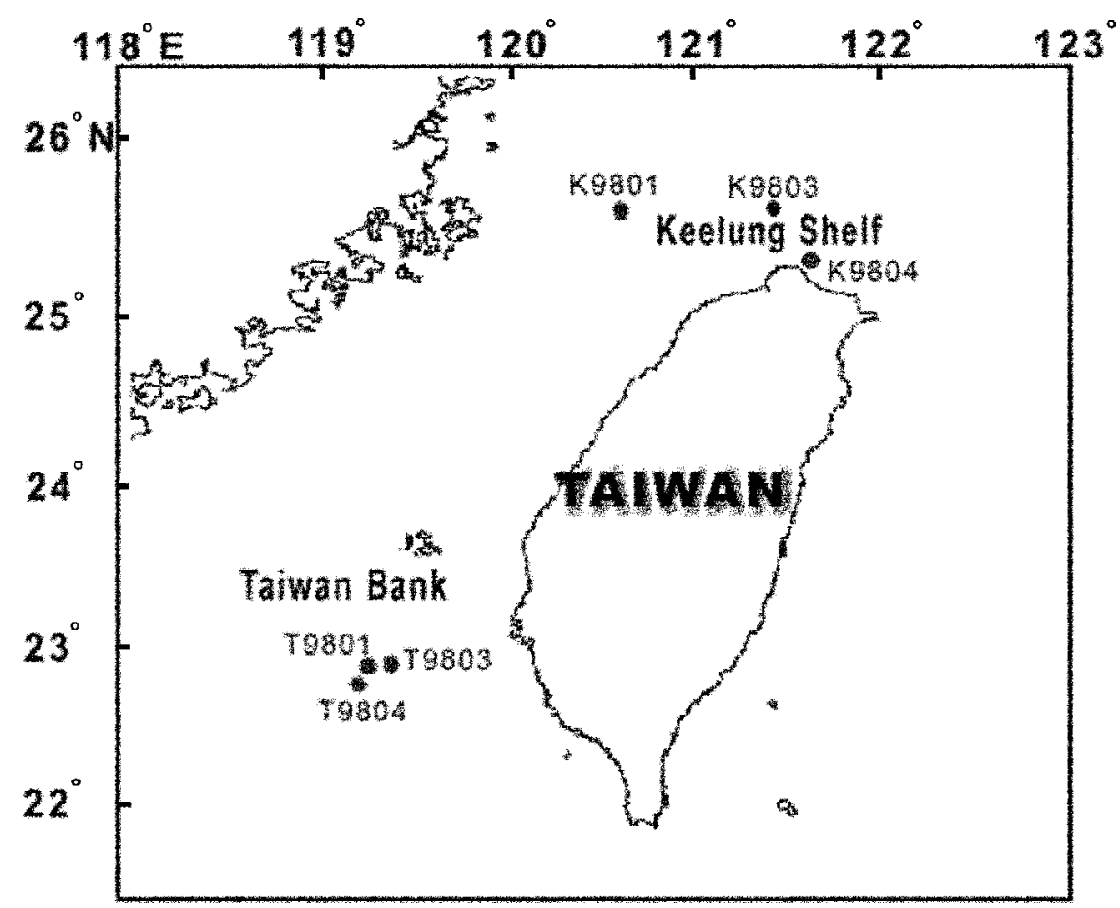

Fig. 1. Map showing sampling locations on the the Keelung Shelf and the Taiwan Bank.

Table 1. Sampling information of Portunus sanguinolentus collected for the present study, in which the effective sample size is total specimens used in the present study after outliers diagnosis.

\begin{tabular}{lccccc}
\hline \multirow{2}{*}{ Samples } & \multirow{2}{*}{ Groups } & \multicolumn{2}{c}{ Sampling locations } & Collected & Effective \\
& & Longitude & Latitude & Times & Sample size \\
\hline \multirow{2}{*}{ K9801 } & \multirow{2}{*}{ Keelung Shelf } & $120^{\circ} 40^{\prime}$ & $25^{\circ} 40^{\prime}$ & Jan 1998 & 54 \\
K9803 & $121^{\circ} 30^{\prime}$ & $25^{\circ} 40^{\prime}$ & Mar 1998 & 26 \\
K9804 & & $121^{\circ} 42^{\prime}$ & $25^{\circ} 15^{\prime}$ & Apr 1998 & 26 \\
\hline T9801 & & $119^{\circ} 18^{\prime}$ & $22^{\circ} 54^{\prime}$ & Jan 1998 & 51 \\
T9803 & Taiwan Bank & $119^{\circ} 22^{\prime}$ & $22^{\circ} 57^{\prime}$ & Mar 1998 & 49 \\
T9804 & & $119^{\circ} 16^{\prime}$ & $22^{\circ} 53^{\prime}$ & Apr 1998 & 58 \\
\hline
\end{tabular}


fifth abdominal segment length; $\mathrm{CH}$, chela length; $\mathrm{CHW}$, chela width; $\mathrm{CHP}$, movable dactylus length) were taken to study (Fig. 2). The characters were measured using precision Vernier calipers to the nearest $0.01 \mathrm{~mm}$.
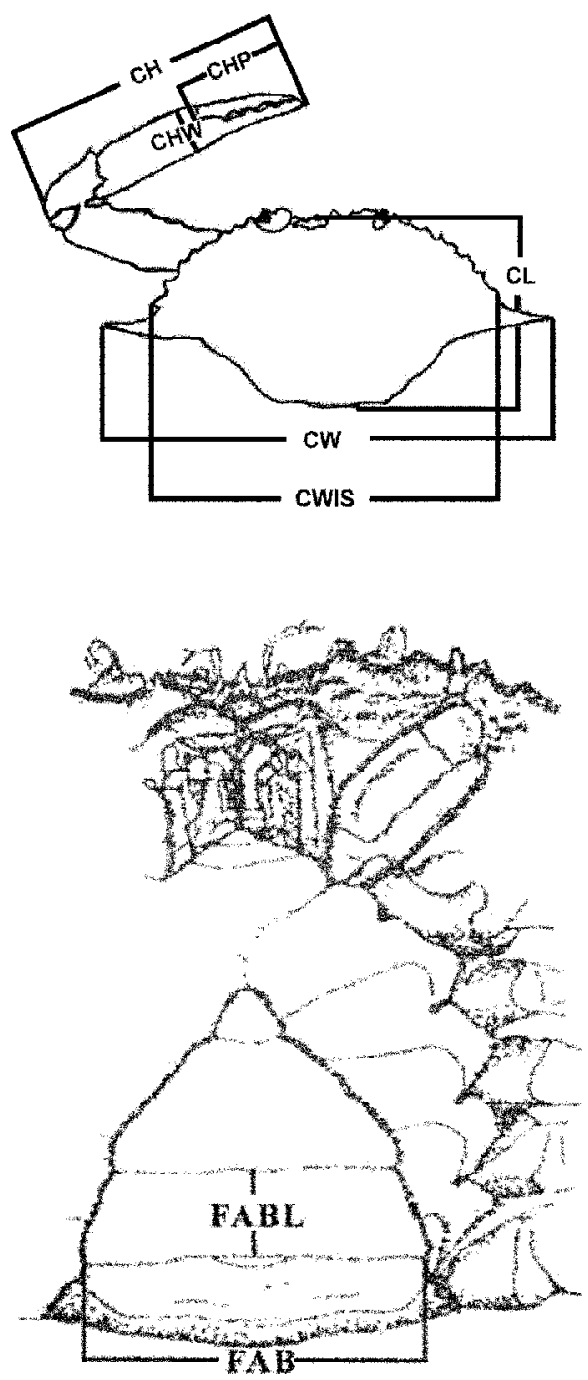

Fig. 2. The main portions of Portunus sanguinolentus to illustrate eight morphometric characters forming datasets for multivariate analysis, where $\mathrm{CW}$ is carapace width; CL, carapace length; CWIS, distance between two sides of first spine; FAB, fifth abdominal segment width; FABL, fifth abdominal segment length; $\mathrm{CH}$, chela length; $\mathrm{CHW}$, chela width; and CHP, movable dactylus length. 


\subsection{Data diagnosis and size adjustment}

Considering allometric growth (Hsu et al. 2000), all measurements were log-transformed before statistical analyses. Potential biases in the datasets may exist in the $\mathrm{CH}$ variable since crabs can autotomize appendages to escape and avoid danger, and missing appendages undergo one or more molts to recover their former sizes. Consequently, undersized regenerating appendages may introduce deviations apart from the expected normal deviations.

Data diagnosis and size adjustments preceded statistical analysis. To do so, Cook's distance was used to diagnose outliers by the regression of each chela length on carapace width for individual samples; and the Burnaby method (Burnaby 1966) was used to size adjust to reduce process errors due to size discrepancies.

The Cook's distance $\left(D_{i}\right)$ is a metric measurement for deciding how a particular point alone is to influence regression estimates by measuring the change of the sum of squared differences for every $i$ th observation when the $i$ th point is removed (Cook and Weisberg 1998), i.e., a standardized average squared disparity between the two sets of coefficients. Let $\hat{\eta}_{(i)}$ and $\hat{\eta}$ be the vector of $k$ regression coefficients with the $i$ th observation deleted and the vector of $k$ regression coefficients for the full dataset respectively, then, $D_{i}$ can be computed by:

$$
D_{i}=\frac{\left(\hat{\eta}_{(i)}-\hat{\eta}\right)^{T}\left(U^{T} U\right)\left(\hat{\eta}_{(i)}-\hat{\eta}\right)}{k \hat{\sigma}^{2}}
$$

where $U$ ( $U^{T}$, the transposed $U$ ) is the $\mathrm{n} \mathrm{x}$ k matrix including an initial column of $1 \mathrm{~s}$ (ones) for the intercept. Hence $U^{T} U$ is the cross-product matrix used to generate the predicted values. The denominator of equation (1) standardizes the formula by a scale factor $k$ to take account of the variability around the regression fit and the number of coefficients. Hence, samples were excluded from subsequent analyses when $D_{i}$ is larger than 0.5 .

The Burnaby's size adjustment was done by projecting measurements onto a hyperplane orthogonal to the specified vector by postmultiplying the $n$ by $p$ matrix of the character data by a $p$ by $p$ symmetric matrix, $\boldsymbol{L}$, defined as:

$$
L=I_{p}-\left(V^{T} V\right)^{-1} V^{T},
$$

where $n$ is the number of observations, $p$ is the number of variables, $I_{p}$ is a $p$ by $p$ identity matrix, $V$ is the isometric size eigenvector, and $V^{T}$ is the transpose of matrix $V$ (Rohlf and Bookstein 1987). For morphometric comparisons to identify populations, the resultant adjusted data matrix, $L$, was used first to extend the hierarchical cluster analysis by the unweighted pair-group method with arithmetic means (UPGMA; Sneath and Sokal 1973) and then to the canonical discriminant analysis.

\subsection{Statistical analyses of external morphometric characters}

Hierarchical cluster analysis is a statistical method for finding relatively homogeneous 
clusters of cases based on measured characteristics. Using measured distances, the hierarchical tree is always applied to join homogeneous groups together into successively larger clusters. For instance, the distance between two clusters can be calculated for UPGMA, as the average distance of all data measurements in two different groups, and represented by the Euclidian distance. The Euclidian distance (x,y) is the measurement among centers of the $p$-characters between two groups. Then, let the characters measured be $X=\left(x_{1}, x_{2}, \ldots, x_{p}\right)$ for the group one and $Y=\left(y_{1}, y_{2}, \ldots, y_{p}\right)$ for the others, the Euclidian distance would be:

$$
D^{2}(x, y)=\left(x_{1}-y_{1}\right)^{2}+\left(x_{2}-y_{2}\right)^{2}+\ldots+\left(x_{p}-y_{p}\right)^{2} .
$$

Canonical discriminant analysis is a dimension-reduction technique related to principal component analysis and canonical correlation. Given a classification variable and several interval variables, the canonical discriminant analysis derives canonical variables (linear combinations of the interval variables) that summarize between-class variation similar to the principal component analysis that summarizes total variation.

Accordingly, the analysis proceeded as follows: 1) the two sample groups, represented by six sampling subgroups (three for each group), were denoted by swarms of points for the eight morphometric characters, i.e., 8-dimensional space centered at a point and characterized by mean vectors that disperse about this point in ellipsoidal shape described by a variance-covariance (V-C) matrix, 2) the eigenvalues of the V-C matrix and the Bartelett's criterion were used to decide how many eigenvalues obtained contribute significantly to the identification of the six sampling subgroups, 3 ) the mean vectors (6 elements) representing each of the six sampling subgroups were illustrated in canonical form, and 4) the six mean vectors were used with their corresponding centers and $90 \%$ confidence intervals as radii to illustrate the $90 \%$ ellipsoidal regions. Consequently, comparisons were achieved.

\subsection{Analysis of maturity curves}

Crabs used in this approach were collected during October 1997 to April 1998. Totals of 511 and 873 female individuals were collected for the Keelung Shelf and Taiwan Bank respectively to analyze size at maturity. Maturity of specimens was determined following the same method as described in Hsu et al. (2000).

The size (carapace width) at $50 \%$ maturity, $\mathrm{LM}_{50}$, was estimated by fitting a logistic maturity model with the proportion of maturity on carapace width (Somerton 1980; 1981). The logistic maturity model is given by

$$
P(L)=\frac{1}{1+e^{-(a+b L)}},
$$

where $P(L)$ is the probability that a crab with carapace width $L \mathrm{~mm}$ is mature, and $a$ and $b$ are parameters to be estimated, usually $a<0$ and $b>0$ were found. The logistic equation is symmetrical at its $\mathrm{LM}_{50}$, which is given by 


$$
\mathrm{LM}_{50}=-\frac{a}{b}
$$

The comparison between individual parameters uses asymptotic standard errors which were obtained from the maximum likelihood estimation (MLE) for parameters of logistic maturity equations. Tests of significance among logistic models usually use likelihood ratio tests based on an asymptotic Chi-square (Sokal and Rohlf 1995; Quinn and Deriso 1999). Tests for equality of parameters between datasets based on the theory of likelihood ratio tests have been introduced by several scientists such as Kimura (1980), Cerrato (1990) and Quinn and Deriso (1999). The likelihood ratio tests can be used to compare full models with a reduced model for two or more datasets. By assuming a normal distribution with additive errors for five data sets, the maximum likelihood estimation $\left(\mathrm{MLE}_{\mathrm{i}}\right)$ of parameters $\hat{\Theta}_{i}$, and standard deviation $\hat{\sigma}_{i}$ for data set $i, Y_{i}$ with sample size, $n_{i}$ results in:

$$
\max \ln L_{i}\left(\hat{\Theta}_{i}, \hat{\sigma}_{i} \mid\left\{Y_{i}\right\}\right)=-\frac{n_{i}}{2}\left[\ln \left(2 \pi \hat{\sigma}_{i}\right)+1\right],
$$

and

$$
\hat{\sigma}_{i}^{2}=\frac{1}{n_{i}} \sum_{j=1}^{n_{i}}\left(Y_{i j}-\hat{Y}_{i}\right)^{2}
$$

The joint maximum $\log$ likelihood $\ln L_{F}$ for the full model is obtained by:

$$
\ln L_{F}=\sum_{i=1}^{R} \max \ln L_{i}
$$

Meanwhile, the maximum $\log$ likelihood for a reduced model, $\ln L_{R}$, is deduced from (8) with $n_{i}$ and $\hat{\sigma}_{i}^{2}$ replaced by $n$ and $\hat{\sigma}^{2}$. The resultant likelihood ratio test statistics being:

$$
\chi^{2}=-2 \ln \left(\frac{L_{R}}{L_{F}}\right)
$$

The asymptotic distribution is a chi-square distribution with degrees of freedom equal to the difference in the degrees of freedom between the full model and reduced model.

The hypothesis test is $\Theta_{i}=\Theta_{j}$ for all pairs $(i, j)$ vs. $\Theta_{i} \neq \Theta_{j}$ for at least one pair $(i, j)$. There are $D F=R p-p=(R-1) p$ degrees of freedom, where $R$ is the number of datasets and $p$ is the number of parameters. A significant ratio indicates that a reduced model is not statistically similar to the full model. The standard error of $\mathrm{LM}_{50}$ was computed using the delta 
method (Somerton 1980; Seber 1982; Cox 1990) to estimate the confidence interval.

All analyses in this study were performed using Statistical Analysis System software (SAS Institute Inc. 1985) and NTSYS (Rohlf 1993), and all statistical tests were done at $5 \%$ probability (P) level of significance.

\section{RESULTS}

\subsection{Samples diagnosis}

The use of Cook's distance indicated that two samples were outliers, one from the sample group collected in January 1998 from the Taiwan Bank, and the other from the sample group collected in April 1998 from the Keelung Shelf. These two samples were deleted in the following analyses. The final sampling data used in the present analysis have been summarized in Table 1 . The correlation analysis revealed that they were highly mutually correlated in each other's characters (all correlation coefficients are between 0.98 and 0.59). This indicates the desirability of analyzing response variables jointly rather than separately by series of univariate analyses (Kleinbaum et al. 1998). However, the carapace width, which was used as the covariate in the study, presented low overlap between samples (Fig. 3).

\subsection{Canonical discriminant analysis}

As illustrated in the hierarchical dendrogram (Fig. 4) obtained from UPGMA analysis, each group joined together into successively larger clusters. Comparisons of computed Euclidian distance (Table 2) indicate a concise result such that the discrepancies were obvious for all the selected external morphometric characters between two sample groups.

The examination of eigenvalues obtained from the canonical analysis (Table 3) showed that the first six eigenvalues were significant $(\mathrm{P}<0.0001)$. As estimated, the cumulated contributions of variability are $40.33 \%, 63.21 \%, 79.62 \%, 87.50 \%, 94.24 \%$ and $100 \%$ from the first to the sixth eigenvalue, respectively. Moreover, the data when compared with Wilk's Lambda indicate that there were significant differences between the two groups (Keelung Shelf and Taiwan Bank) in external morphometric characters for Portunus sanguinolentus (Wilk's Lambda $=0.5872, \mathrm{P}<0.001)$. Furthermore, the first two canonical variables $(63.21 \%$ of the total shape variation) obtained from the canonical discriminant analysis were illustrated with their $90 \%$ ellipsoidal circles (Fig. 5) for each sampling subgroup. The results indicated that two groups might be classified for those six subgroups of Portunus sanguinolentus. In addition, it was established that two groups were clearly from different areas. Hence, our results suggest that two stocks were reasonably identified, i.e., one being the Taiwan Bank stock and the other the Keelung Shelf stock.

\subsection{Size at maturity comparison}

The maturity curves were modeled using logistic equation (4) by sex and area. The parameters of logistic equations were estimated by the maximum likelihood method and their 


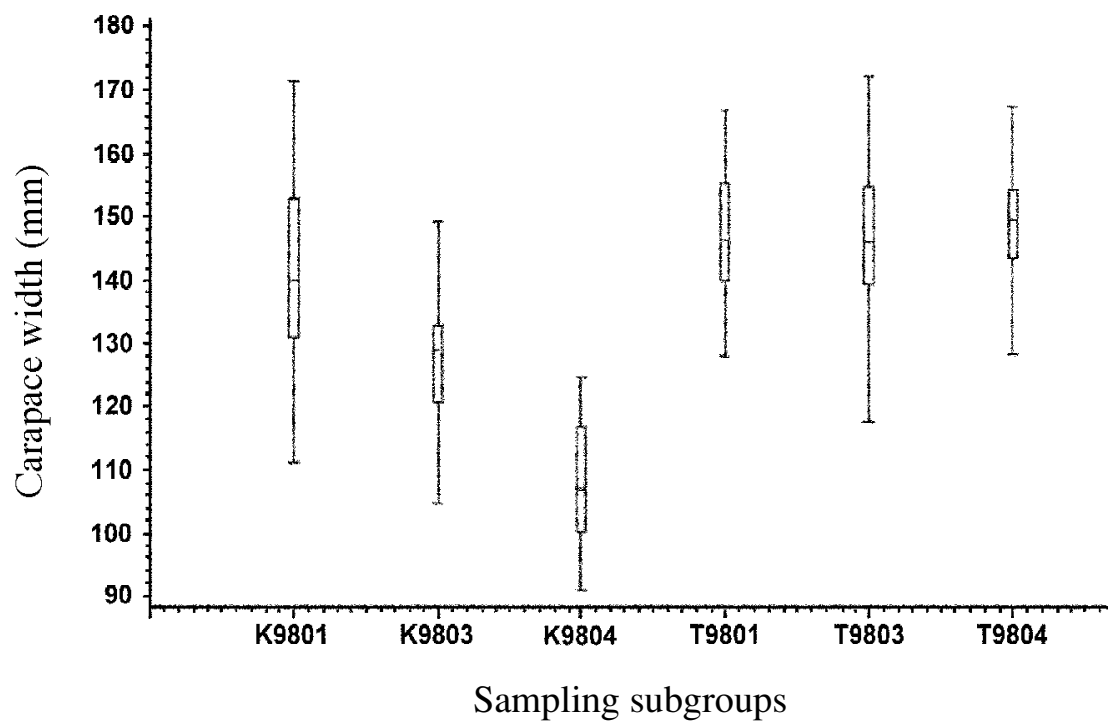

Fig. 3. Box plots for size (carapace width) distribution of Portunus sanguinolentus in each dataset to indicate the mean (horizontal line in rectangular box), the third quartile (Q3, upper boundary of vertical rectangle), the first quartile (Q1, lower boundary of vertical rectangle), and the range (vertical lines).

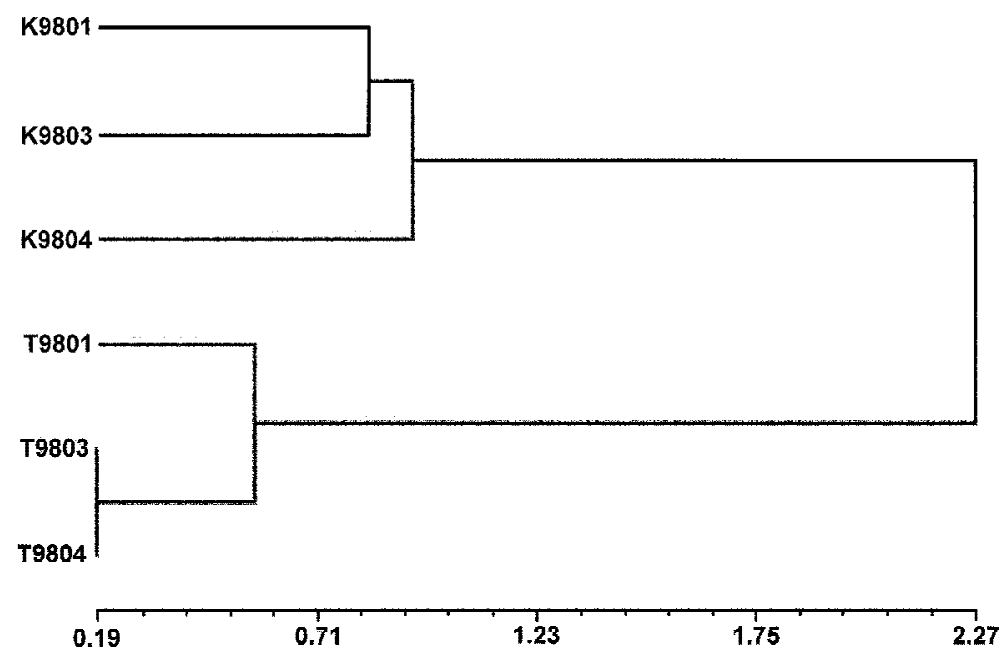

Eculidian distance between the centers of sampling subgroups

Fig. 4. Dendrogram of six datasets sampled from the Keelung Shelf (K9801, K9803, and K9804) and the Taiwan Bank (T9801, T9803, and T9804), where the number line below the dendrogram indicates the Euclidian distance between datasets. 
Table 2. Euclidian distance estimated between each sample of Portunus sanguinolentus, in which a long distance was computed as shown in bold type between two sampling groups.

\begin{tabular}{lrrrrl}
\hline GROUP & K9803 & K9804 & T9801 & T9803 & T9804 \\
\hline K9801 & 0.83279 & 0.95736 & $\mathbf{2 . 6 5 0 1 5}$ & $\mathbf{1 . 4 0 2 0 4}$ & $\mathbf{1 . 3 1 3 1 2}$ \\
K9803 & 0 & 0.91247 & $\mathbf{2 . 4 9 6 1 5}$ & $\mathbf{1 . 3 7 1 8 8}$ & $\mathbf{1 . 8 5 0 4 4}$ \\
K9804 & & 0 & $\mathbf{3 . 8 4 6 7 5}$ & $\mathbf{2 . 6 8 0 4 2}$ & $\mathbf{2 . 8 4 7 7 7}$ \\
T9801 & & & 0 & 0.58536 & 0.53062 \\
T9803 & & & & 0 & 0.18573 \\
\hline
\end{tabular}

Table 3. The examination of eigenvalues and the hypothesis test for those eigenvalues by Chi-square approach in the present Canonical discriminant analysis using eight morphometric characters of Portunus sanguinolentus $(\mathrm{n}=258)$.

\begin{tabular}{ccccc}
\hline Order $(\mathrm{i})$ & $\begin{array}{c}\text { Eigenvalues } \\
(\phi)\end{array}$ & $\prod_{i=j}^{m}\left(1+\phi_{i}\right)$ & $\begin{array}{c}\text { Chi-square } \\
\left(\chi^{2}\right)^{*}\end{array}$ & $\begin{array}{c}\text { Degree of } \\
\text { Freedom for } \\
\chi^{2}\end{array}$ \\
\hline $1(\mathrm{k}=0)$ & 3.2264 & 101.4159 & 1154.8075 & 40 \\
$2(\mathrm{k}=1)$ & 1.8306 & 23.9958 & 794.4697 & 28 \\
$3(\mathrm{k}=2)$ & 1.3124 & 8.4773 & 534.3480 & 18 \\
$4(\mathrm{k}=3)$ & 0.6298 & 3.6660 & 324.7753 & 10 \\
$5(\mathrm{k}=4)$ & 0.5395 & 2.2494 & 202.6659 & 4 \\
$6(\mathrm{k}=5)$ & 0.4611 & 1.4611 & 94.7974 & 0 \\
$7(\mathrm{k}=6)$ & $\sim 0$ & $\sim 1.0000$ & & 0 \\
8 & 0 & & & \\
\hline
\end{tabular}

* $\chi^{2} \sim\left\{(N-1)-\frac{p+h}{2}\right\} \ln \left\{\prod_{j=k+1}^{m}\left(1+\phi_{i}\right)\right\}$ with $(\mathrm{p}-\mathrm{k})(\mathrm{h}-\mathrm{k}-1)$ degree of freedom when $\phi_{k+1}=\phi_{k+2}=\ldots=\phi_{m}=0$ and $m$ is $\min (p, h-1)$ (Bartlett 1947), where $\mathrm{N}=\mathrm{n}_{1}+\mathrm{n}_{2}+\ldots+\mathrm{n}_{\mathrm{h}}$, and $\mathrm{N}=258 ; p=8, m=6$ (the numbers of non-zero eigenvalue) and $h=6$ in the present analysis. 


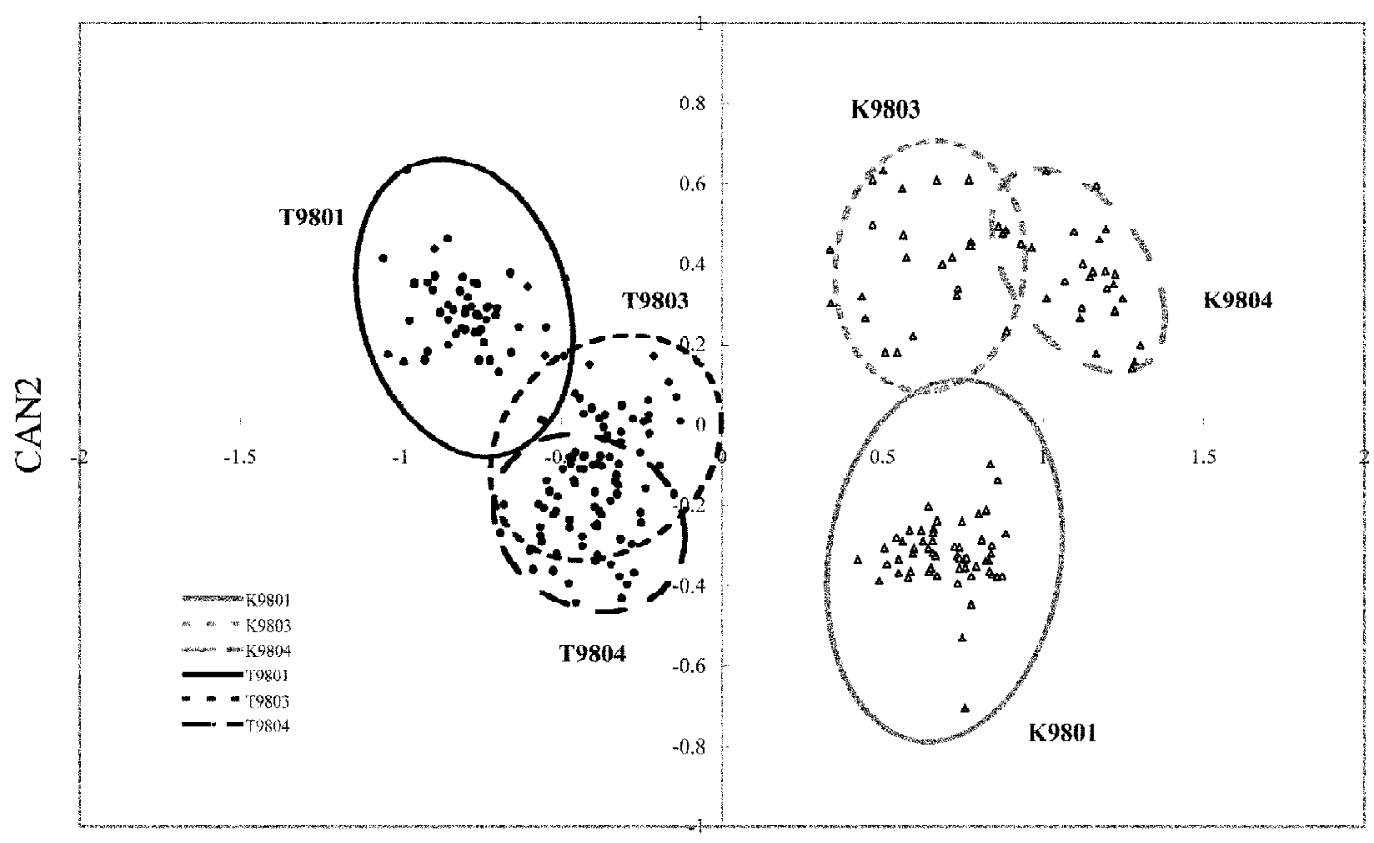

CAN1

Fig. 5. The canonical variates chart showing the mutual relations of six sampling subgroups based on eight morphometric characters, in which circles represent the $90 \%$ ellipsoidal confidence region corresponding to the mean of each subgroup; and where canonical variates are shown with an open triangle and solid circle for data from Keelung Shelf and Taiwan Bank, respectively; and gray circles and black circles represent the $90 \%$ ellipsoidal confidence region for Keelung Shelf and Taiwan Bank, respectively.

equality was tested by likelihood ratio tests. Thus, the comparison indicated that for females, there was statistically significant difference between sampling areas (reject $\mathrm{H}_{0}$ : $\Theta_{\text {keelung Shelf }}=\Theta_{\text {Taiwan Bank }}, \chi^{2}=10.8613, \mathrm{P}=0.0010^{* *}$ ); yet for males, the difference was not statistically significant $\left(\chi^{2}=0.5686, \mathrm{P}=0.4508\right.$ ). Consequently, three logistic maturity curves (Fig. 6), two for females' in both areas and one for males for a combined area, were obtained as:

Maturity curve for females:

$$
\text { Keelung Shelf: } P(L)=\frac{1}{1+e^{-(11.6663-0.1203 L)}}
$$




$$
\begin{aligned}
& \text { Taiwan Bank: } P(L)=\frac{1}{1+e^{-(5.4520-0.0662 L)}} \text {; } \\
& \text { Maturity curve for males: } P(L)=\frac{1}{1+e^{-(9.2532-0.0999 L)}} \text {. }
\end{aligned}
$$

Further, the $\mathrm{LM}_{50}$ was estimated by equation (5) with above estimated parameters and its 95\% confidence interval was computed using the delta method. Therefore, as Table 4 shows, $\mathrm{LM}_{50}$ was estimated theoretically at about $97.00 \mathrm{~mm} \mathrm{CW}$ and $82.36 \mathrm{~mm} \mathrm{CW}$ for females in the Keelung Shelf and Taiwan Bank, respectively; and $92.62 \mathrm{~mm} \mathrm{CW}$ for males in the combined area. The statistical comparison of $\mathrm{LM}_{50}$ for females between areas was tabulated in Table 4, indicating that there were statistically significant differences between areas.

\section{DISCUSSIONS}

Within this study, the "stock" is considered to be an intra-specific group of individuals that exhibit specific phenotypic attributes in response to environmental and biological factors, then according to the current results of the morphometrics analysis and $\mathrm{LM}_{50}$ comparisons, two distinct Portunus sanguinolentus stocks may be proposed around the waters off Taiwan. Without any additional distribution information of Portunus sanguinolentus in the Taiwan Strait, the distribution boundary of the two stocks may be an interesting and essential topic in the zoogeographical study of the species. However, different topographic and oceanographic environments (Anonymous 2000) may reasonably explain the result of this fact of stock separation.

In contrast to a linear comparison, a new geometric method may provide more complicate stereo-morphological comparisons and obtain more satisfactory results (Baylac and Penin 1998). In addition, meaningful shape characters can make for the most useful group discriminators (Bookstein 1996). The multivariate approach is best for isolating shape difference because multivariate techniques use a composite measure of general body size that reflects the average value of traits for each individual (Strauss 1993). A general size measure averages the random variation inherent in individual traits, thereby reducing statistical noise and providing a more comprehensive description of the amount and direction of shape change (Cavalcanti et al. 1993; 1999; Strauss 1993).

Because the goal of morphometrics is the study of size and shape variation, one of the basic steps often required is standardization for size. Various techniques for removal of size have been inquired into for obtaining size-free morphometric data, such as regression techniques (Reist 1985), the ratio method (Avsar 1994), shearing principal components analysis (Humphries et al. 1981), and Burnaby's method (Burnaby 1966). Burnaby's method can effectively diagnose sized-related variation within a group from between-group difference (Bookstein et al. 1985). The morphometric data sets adjusted by Burnaby's method have one dimension less but with the advantage that subsequent analysis made with this data matrix can 
A.) Females

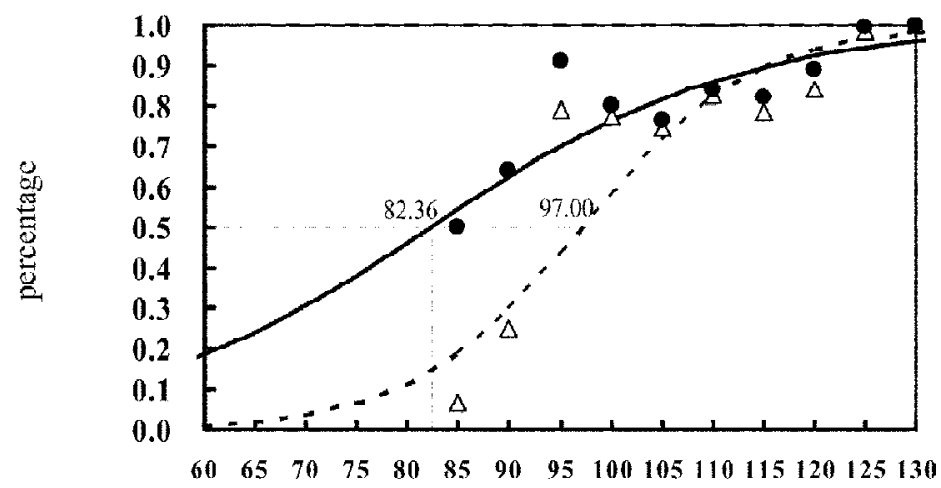

Carapace Width (mm)

B.) Males

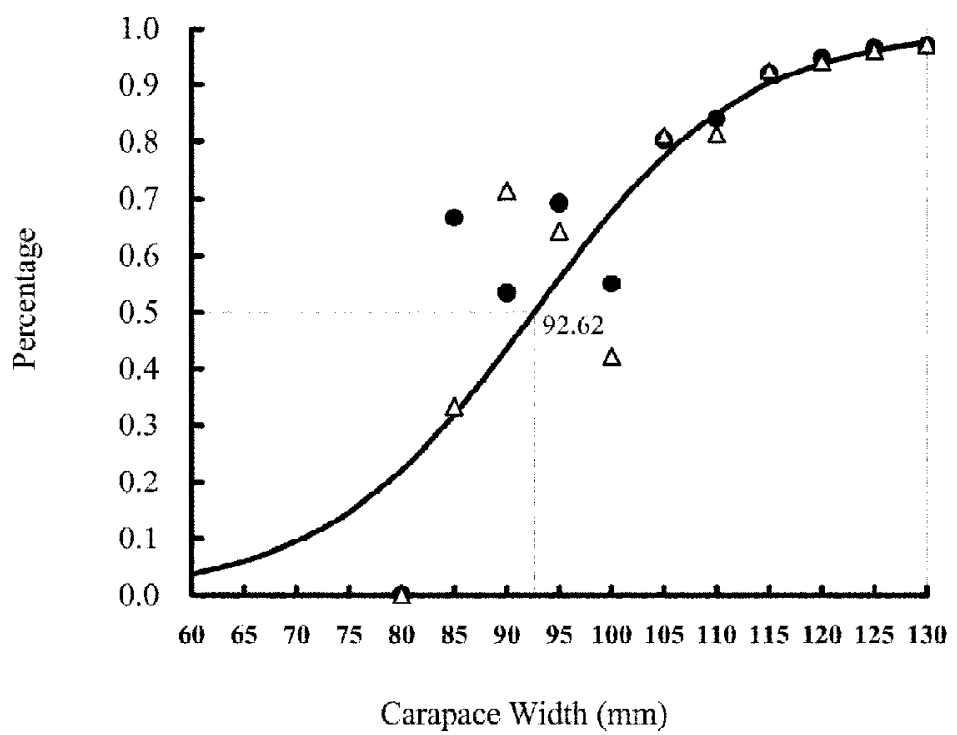

Fig. 6. Logistic maturity curves of Portunus sanguinolentus from the Keelung Shelf and Taiwan Bank, respectively. A) Female maturity curves with a dotted and solid lines to represent the fitted logistic curves for samples from the Keelung Shelf and the Taiwan Bank, respectively. B) the male maturity curve. 
Table 4. The goodness of fit and parameter estimate of logistic equation and the estimation of $\mathrm{LM}_{50}$ for Portunus sanguinolentus from Keelung Shelf and Taiwan Bank, in which the comparison of logistic equations were made by likelihood ratio test, and $a$ and $b$ are two parameters of logistic equation. $* *$ denotes significance at $1 \%$, and (ns) indicates that the test is not significant at $5 \%$.

\begin{tabular}{|c|c|c|c|}
\hline & \multicolumn{2}{|c|}{ Feamles } & Males \\
\hline & \multicolumn{2}{|c|}{ Sample areas } & \\
\hline & Keelung Shelf & Taiwan Bank & \\
\hline Sample size & 511 & 865 & 1036 \\
\hline Immature & 127 & 116 & 176 \\
\hline Mature & 384 & 749 & 860 \\
\hline$a$ & -11.6663 & -5.4520 & -9.2532 \\
\hline $95 \%$ confidence interval & $(-13.8223,-9.5103)$ & $(-7.3032,-3.6008)$ & $(-11.7193,-6.7871)$ \\
\hline $\mathrm{SD}$ & 1.1000 & 0.9445 & 1.2582 \\
\hline$b$ & 0.1203 & 0.0662 & 0.0999 \\
\hline $95 \%$ contidence interval & $(0.1003,0.1403)$ & $(0.0491,0.0833)$ & $(0.0768,0.1230)$ \\
\hline SD & 0.0102 & 0.0087 & 0.0118 \\
\hline $\mathrm{LM}_{50}$ & 97.00 & 82.36 & 92.62 \\
\hline $95 \%$ confidence interval & $(95.46,98.54)$ & $(77.28,87.54)$ & $(89.95,95.29)$ \\
\hline $\mathrm{SD}$ & 0.7838 & 2.6170 & 1.3611 \\
\hline $\mathrm{R}^{2}$ & 0.7603 & 0.6314 & 0.7030 \\
\hline $\mathrm{H}_{0}: \Theta_{\text {Keelung Shelf }}=\Theta_{\mathrm{T}}$ & an Bank & & \\
\hline Likelihood ratio & 10.86 & & $0.5686^{(\mathrm{ns})}$ \\
\hline $\mathrm{P}$ & 0.00 & & 0.4508 \\
\hline
\end{tabular}

be interpreted as containing size free information. In addition, the use of nonlinear transformations sharpened some of the findings, and reduced the effect of some outlier observations. Therefore, log-transforming data, in the present study, can generate a nearly normal distribution, eliminate the effect of scale on variances (LaBarbera 1989), and decouple means from variances to ensure independence of data sets (Underwood 1997).

The multivariate approach, particularly in cluster analysis, is sensitive to outliers (Johnson and Wichern 1998). Therefore, outlier identification is important in application of multivariate 
Table 5. Comparison of size at sexual maturity (carapace width in mm) among Portunus sanguinolentus from different waters.

\begin{tabular}{|c|c|c|c|c|}
\hline \multirow[b]{2}{*}{ Sampling regions } & \multicolumn{3}{|c|}{ Size at maturity ( $\mathrm{CW}$ in $\mathrm{mm}$ ) } & \multirow[b]{2}{*}{ Author(s) } \\
\hline & $\mathrm{LM}_{50}$ & $\begin{array}{l}\text { Minimum } \\
\text { maturation }\end{array}$ & $\begin{array}{c}\text { Maximum } \\
\text { immaturation }\end{array}$ & \\
\hline \multicolumn{5}{|l|}{ Female } \\
\hline $\begin{array}{l}\text { Keelung Shelf } \\
\qquad\left(26^{\circ} \mathrm{N} \text { latitude }\right)\end{array}$ & 97.00 & 82.38 & 120.10 & This paper \\
\hline $\begin{array}{l}\text { Taiwan Bank } \\
\qquad\left(23^{\circ} \mathrm{N} \text { latitude }\right)\end{array}$ & 82.36 & 79.11 & 126.24 & This paper \\
\hline $\begin{array}{l}\text { Indian waters } \\
\qquad\left(19^{\circ} \mathrm{N} \text { latitude }\right)\end{array}$ & - & $81-85$ & -- & Jacob et al. 1990 \\
\hline $\begin{array}{l}\text { Australian waters } \\
\qquad\left(27^{\circ} \mathrm{S} \text { latitude }\right)\end{array}$ & -- & 74.00 & -- & Sumpton et al. 1989 \\
\hline \multicolumn{5}{|l|}{ Male } \\
\hline $\begin{array}{l}\text { Keelung Shelf } \\
\qquad\left(26^{\circ} \mathrm{N} \text { latitude }\right)\end{array}$ & 92.62 & 80.35 & 120.10 & This paper \\
\hline $\begin{array}{l}\text { Taiwan Bank } \\
\qquad\left(23^{\circ} \mathrm{N} \text { latitude }\right)\end{array}$ & 92.62 & 83.09 & 127.46 & This paper \\
\hline $\begin{array}{l}\text { Indian waters } \\
\qquad\left(19^{\circ} \mathrm{N} \text { latitude }\right)\end{array}$ & 100.00 & -- & -- & Reeby et al. 1990 \\
\hline $\begin{array}{l}\text { Australian waters } \\
\qquad\left(27^{\circ} \mathrm{S} \text { latitude }\right)\end{array}$ & -- & 83.00 & -- & Sumpton et al. 1989 \\
\hline
\end{tabular}

analysis (Rousseeuw and van Zomeren 1990). An outlier in the data may indicate special circumstances warranting further investigation, e.g., the presence of an unanticipated interaction effect. Therefore, it is inappropriate to immediately discard the observation unless strong evidence indicates that it resulted from a mistake, e.g., an error in data recording or some other cause independent of the process under study, such as an obvious instrument malfunction. The identification of outliers is usually based on robust regression diagnostic statistics, such as jackknife residuals (Belsley et al. 1980), leverages (Stevens 1984), and Cook's distance (Cook and Weisberg 1998), etc.

The $\mathrm{LM}_{50}$ of female Portunus sanguinolentus was observed to present a slightly larger size in Keelung Shelf than in Taiwan Bank. Though a shortage of small sized crabs was apparent in the samples affecting the maturity curve, and tending the $\mathrm{LM}_{50}$ estimation to bias, the $\mathrm{LM}_{50}$ of female Portunus sanguinolentus obtained from different waters (Table 5) shows that 
a related geographical differences in size at maturity is dependent on the latitudinal gradient. Quinn and Kojis 1987 suggested that crabs matured at smaller size in lower latitudes than in higher latitudes. The current estimates of $\mathrm{LM}_{50}$ are coincident with this geographical tendency. However, there were populations that did not fit this rule, such as the mangrove crab (Perrine 1978), tanner crab (Somerton 1981), and red king crab (Powell et al. 1983). The female Portunus sanguinolentus in the Indian waters $\left(19^{\circ} \mathrm{N}\right.$ latitude) inhabits a lower latitude, but matures to a larger size.

Identification of exploitable stocks is necessary for a number of reasons including allocation of catch among competing fisheries, recognition and protection of nursery and spawning areas, and for development of optimal harvests with monitoring strategies (Begg et al. 1999). Since, some fisheries occur on mixed-stocks, it is essential to identify and quantify the various stock components that comprise these mixed-stocks. Also fishing pressures can affect genetic diversity whilst ignorance of stock structure can lead to dramatic changes in the biological attributes, and ineffective fisheries management, e.g., the genetic diversity and low productivity rates of a species (Smith et al. 1991). As a result, misleading results of stock identification can collapse low scale component stock in multi-species fisheries. Moreover, the aquatic organisms are more "plastic" than many animal taxa, showing higher coefficients of variation of life history and morphological features (Allendorf et al. 1987). Therefore, stock identification should be more careful in using morphometric characters than in other techniques, such as genetic biomarkers. Hence, in the future, the comparison of external morphometric characters studies may proceed with the investigation of genetic variations in order to obtain more concrete and accurate results.

Acknowledgements We thank the National Science Council, R.O.C. for supporting the research project in contract no. NSC86-2611-B-002-A-001, NSC89-2313-B002-067 and NSC892313-B002-167 to Dr. Hsu. Appreciation is extended to Ms. Stacy Kao, Research Assistant of the Tuna Research Center, Institute of Oceanography, National Taiwan University, who helped in collecting and measuring crab samples. Our many thanks are also given to two anonymous referees for their valuable and constructive comments.

\section{REFERENCES}

Allendorf, F. W., N. Ryman, and F. Utter, 1987: Genetics and fishery management: past, present, and future. In: Ryman, N. and F. Utter, (Eds.), Population Genetics and Fishery Management. Washington Sea Grant Program, Seattle, 1-19.

Anonymous, 2000: Oceanographic data maps in 1999. National Center of Oceanographic Research, National Science Council and National Taiwan University. 114pp. (in Chinese)

Avsar, D., 1994: A stock differentiation study of the sprat (Sprattus sprattus phalericus Risso) off the southern coast of the Black Sea. Fish. Res., 19, 363-378.

Barltett, M. S., 1947: Multivariate analysis. J. Royal Stat. Soc., 9, 167-197. 
Baylac, M., and X. Penin, 1998: Wing static allometry in Drosophila simulans males (Diptera, Drosophilidae) and its relationships with developmental compartments. Acta Zool. Acad. Sci. Hungaricae, 44, 97-112

Begg, G. A., K. D. Friedland, and J. B. Pearce, 1999: Stock identification and its role in stock assessment and fisheries management: an overview. Fish. Res., 43, 1-8.

Belsley, D. A., E. Kuh, and R. E. Welsch, 1980: Regression Diagnostics: Identifying influential data and sources of collinearity. John Wiley and Sons. NY.

Bookstein, F. L, 1996: Combining the tools of geometric morphometrics. In: Advances in Morphometrics, Marcus, L. F. et al. (Eds.) Plenum Press, New York, 131-151

Bookstein, F. L., B. Chernoff, R. L. Elder, J. M. Humphries, G. R. Smith and R. E. Strauss, 1985: Morphometrics in evolutionary biology: the geometry of size and shape change with examples from fishes. Acad. Natl. Sci. Philadel., 15, 277P.

Bowering, W. R., R. K. Misra, and W. B. Brodie, 1998: Application of a newly developed statistical procedure to morphometric data from American plaice (Hippoglossoides platessoides) in the Canadian northwest Atlantic. Fish. Res., 34, 191-203.

Burnaby, T. P., 1966: Growth-invariant discriminant functions and generalized distances. Biometrics, 22, 96-110.

Campbell, G. R., and D. R. Fielder, 1986: Size at sexual maturity and occurrence of ovigerous females in three specious of commercially exploited crabs in southeast Queenland. Proc. Bombay Nat. History Soc., 54, 399-439.

Cavalcanti, M. J., and P. R. D. Lopes, 1993: Multivariate morphometric analysis of five species of Serranidae (Teleostei: Perciformes). Acta Biol. Leopoldensia, 15, 53-64.

Cavalcanti, M. J., L. R. Monteiro, and P. R. D. Lopes, 1999: Landmark based morphometric analysis in selected species of serranid fishes (Perciformes: Teleostei).Zool. Stud., 38, 287-294.

Chu, K. H., Q. C. Chen, L.M. Huang, and C. K. Wong, 1995: Morphometric analysis of commercially important penaeid shrimps from the Zhujiang estuary, China.Fish. Res., 23,83-93.

Cox, C., 1990: Fieller's Theorem, The Likelihood and the Delta Method, Biometrics. 46, 709718.

Harriet, P., B. Walter, T. Christine, and S. Kenneth, 1995: Fishery-related morphometric characteristics of Menippe adina from the north-Central Gulf of Mexico.North Am. J. Fish. Manage., 15, 639-646.

Hartnoll, M. G., 1969: Mating in the Brachyura. Crustaceana., 16, 161-181.

Hobbs, R. C., L. W. Botsford, and A. Thomas, 1992: Influence of hydrographic conditions and wind forcing on the distribution and abundance of Dungeness crab, Cancer magister, larvae. Can. J. Fish. Aquat. Sci., 49, 1379-1388.

Hsu, C. C., H. C. Chang, and H. C. Liu, 2000: Sex-variant morphometrics of the swimming crab, Portunus sanguinolentus (Herbst), from the waters off Northern Taiwan. J. Fish. Soc. Taiwan, 27, 175-185.

Humphries, J. M., FL Bookstein, B. Chernoff, G. R. Smith, R. L. Elder, and S. G. Poss, 1981: Multivariate discrimination by shape in relation to size. Syst. Zool., 30, 291-308. 
Jacob, R. P. N. Prasad, and M. S. Kusuma, 1990: Maturity and dimensional studies in female crabs of Protunus sanguinolentus and Protunus pelagicus decapoda Protunidae. Indian J. Marine Sci., 19, 221-223.

Johnson, D. F., L. W. Botsford, R. D. Methot Jr., and T. C. Wainwright, 1986: Wind stress and cycles in Dungeness crab, Cancer magister, catch off California, Oregon, and Washington. Can. J. Fish. Aquat. Sci., 43, 838-845.

Johnson, D. R., B. S. Hester, and J. R. McConangha, 1984: Studies of a wind mechanism influencing the recruitment of blue crabs in the Middle Atlantic Bight. Continental shelf Res., 3, 425-437.

Johnson, R.A., and D.W. Wichern, 1998: Applied Multivariate Statistical Analysis, 4 ed. Englewood Cliffs, New Jersey, USA. Prentice-Hall.

Kleinbaum, D. G., L. L. Kupper, and K. E. Muller, 1998: Applied regression analysis and other multivariable methods. Duxbury Press, California, 798P.

LaBarbera, M., 1989: Analyzing body size as a factor in ecology and evolution. Annu. Rev. Ecol. Syst., 20, 97-117.

Lee, H. H., and C. C. Hsu, 2003: Population biology of the swimming crab Portunus sanguinolentus in the waters off northern Taiwan. J. Crustacean Biol., 23, 691-699.

Melvin, G. D., M. J. Dadswell, and J.A. Mckenzie, 1992: Usefulness of meristic and morphometric characters in discriminating populations of American shad (Alosa sapidissima) (Ostreichthyes; Clupeidae) inhabiting a marine environment. Can. J. Fish. Aquat. Sci., 49, 266-280.

Mense, D. J., M. H. Posey, T. West, and K. Kincheloe, 1995: Settlement of brachyuran postlarvae along the northern Carolina coast. Bull. Mar. Sci., 57, 793-806.

Overton, J. L., D. J. Macintosh, and R. S. Thorpe, 1997: Multivariate analysis of the mud crab Scylla serrate (Brachyura: Portunidae) from four lovations in Southeast Asia. Mar. Bio., 128, 55-62.

Perrine, D., 1978: The mangrove crab on Ponape. Marine Resources Divison, Ponape, Eastern Caroline Islands, 88P.

Pimentel, R. A., 1979: Morphometrics. Kendall/Hunt Publishing, Dubuque, IA, 276pp.

Powell, G. C., R. Peterson, and L. Schwarz, 1983: The red king crab, Paralithodes camtschatica (Tilesius), in Norton Sound, Alaska: History of biological research and resource utilization through 1982. Alaska Department of Fish and Game Information Leaflet, 222, $1-104$.

Quinn II, T. J., and R. B. Deriso, 1999: Quantitative fish dynamics. Oxford University Press, Oxford. 542pp.

Quinn, N. J., and B. L. Kojis, 1987: Reproductive biology of Scylla spp. (Crustacea: Portunidae) from the Labu estuary in Papua New Guinea. Bull. Mar. Sci., 41, 234-241.

Reeby, J. P. N. Prasad, and M. S. Kusuma, 1990: Size at maturity in the male crabs of Protunus sanguinolentus and Protunus pelagicus. Fish. Tech., 27, 115-119.

Reist, J. D., 1985: An empirical evaluation of coefficients and used in residual and adjustment of size covariation. Can. J. Zool., 64, 1363-1368.

Rohlf, F. J., 1993: NT-SYS, Numerical taxonomy and multivariate analysis system. Exeter Sofeware. 
Rohlf, F. J., and F. L. Bookstein, 1987: A comment on shearing as a method for "size correction”. Syst. Zool., 36, 356-367.

Rousseeuw, P. J., and B.C. van Zomeren, 1990: Unmasking multivariate outliers and leverage points. Journal of the American Statistical Association, 85, 633-651.

Safran, P., 1992: Theoretical analysis of the weight-length relationship in fish juveniles. Mar. Biol., 112, 545-551.

SAS Institute Inc., 1985: SAS user's guide, statistics. SAS Institute Inc., Carry, N.C.

Seber, G. A. F., 1982: The estimation of animal abundance and related parameters, $2^{\text {nd }}$ edition. MacMillan, New York.

Smith, P. J., R. I. C. C. Francis, and M. McVeagh, 1991: Loss of genetic diversity due to fishing pressure. Fish. Res., 10, 309-316.

Sneath, P. H. A., and R. R. Sokal, 1973: Numerical Taxonomy. W. H. Freeman. San Francisco, CA, 573pp.

Sokal R. R., and F. J. Rohlf, 1995: Biometry. The principles and practice of statistics in biological research, $3^{\text {rd }}$ edition. W. H. Freeman and Company, New York. 887pp.

Somerton, D. A., 1980: A computer technique for estimating the size of sexual maturity in crabs. Can. J. Fish. Aquat. Sci., 37, 1488-1494.

Somerton, D. A., 1981: Regional variation in the size of maturity of two species of tanner crab (Chionoecetes bairdi and C. opilio) in the eastern Bering Sea, and its use in defining management subareas. Can. J. Fish. Aquat. Sci., 38, 163-174.

Stephenson, W., and B. Campbell, 1959: The Australian portunids (Crustacea : Portunidae. III. The genus Portunus. Aust. J. Mar. Freshwater Res., 10, 84-124.

Stevens, J. P., 1984: Outliers and influential data points in regression analysis. Psychological Bull., 95, 334-344.

Strauss, R. E., 1993: The study of allometry since Huxley. In: Introductory essay for: Problems of Relative Growth, J.S. Huxley (1932). Johns Hopkins University Press, 47-75.

Sumpton W. D., G. S. Simth, and M. A. Potter, 1989: Notes on the biology of the Portunid crab, Portunus sanguinolentus (Herbst), in subtropical Queensland Waters. Aust. J. Mar. Freshwater Res., 40, 711-717.

Underwood, A. J., 1997: Experiments in ecology: Their logical design and interpretation using analysis of variance. Cambridge Univ. Press, England, 504 pp.

Wenner, A. M., 1972: Sex ratio as a function of size in marine Crustacea.Am. Nat., 106, 321350. 